\title{
The Complex Interplay of Genetic and Lifestyle Risk Factors in Type 2 Diabetes: An Overview
}

\author{
Paul W. Franks ${ }^{1,2,3}$ \\ ${ }^{1}$ Genetic \& Molecular Epidemiology Unit, Department of Clinical Sciences, Skåne University Hospital, Lund University, \\ 20502 Malmö, Sweden \\ ${ }^{2}$ Department of Nutrition, Harvard School of Public Health, Boston, MA 02115, USA \\ ${ }^{3}$ Genetic Epidemiology \& Clinical Research Group, Section for Medicine, Department of Public Health \& Clinical Medicine, \\ Umeå University, 90186 Umeå, Sweden
}

Correspondence should be addressed to Paul W. Franks; paul.franks@med.lu.se

Received 16 August 2012; Accepted 26 September 2012

Academic Editors: A. B. Abou-Samra, G. Da Silva Xavier, and B. R. Gauthier

Copyright ( 2012 Paul W. Franks. This is an open access article distributed under the Creative Commons Attribution License, which permits unrestricted use, distribution, and reproduction in any medium, provided the original work is properly cited.

Type 2 diabetes (T2D) is one of the scourges of modern times, with many millions of people affected by the disease. Diabetes occurs most frequently in those who are overweight or obese. However, not all overweight and obese persons develop diabetes, and there are those who develop the disease who are lean and physically active. Certain ethnicities, especially indigenous populations, are at considerably higher risk of obesity and diabetes than those of white European ancestry. The patterns and distributions of diabetes have led some to speculate that the disease is caused by interactions between genetic and obesogenic lifestyle factors. Whilst to many this is a plausible explanation, remarkably little reliable evidence exists to support it. In this review, an overview of published literature relating to genetic and lifestyle risk factors for T2D is provided. The review also describes the concepts and rationale that have motivated the view that gene-lifestyle interactions cause diabetes and overviews the empirical evidence published to date to support this hypothesis.

\section{Introduction}

T2D imposes an extraordinary burden on affected individuals, their families, and on society as a whole. Diabetic complications are often severe, reducing quality of life and productivity, and causing premature death in many patients. By the year 2030, more than 400 million people globally are projected to have developed T2D [1]. The rising prevalence of diabetes is thought to be driven by four key factors: (i) ageing societies, (ii) improved survival of diabetic patients, (iii) improved surveillance, and (iv) increased prevalence of obesogenic behaviors. Of these explanations, the last, being the only modifiable factor, is unsurprisingly an area of intense discussion and calls to action amongst diabetes policy makers and practitioners.

T2D is diagnosed on the basis of repeated elevated venous blood glucose concentrations when fasted $(\geq 8.0 \mathrm{mmoL} / \mathrm{L})$ or $2 \mathrm{hrs}$ following an oral glucose challenge $(\geq 11.1 \mathrm{mmoL} / \mathrm{L})$, or elevated $(\geq 6.5 \%)$ glycosylated hemoglobin (HbA1c) levels
[2], which are unexplained by other known causes. Insulin is the primary hormone responsible for relocating glucose from the blood into the body's cells. In a healthy resting person, insulin production generally increases soon after glucose is ingested, which initiates a progressive decline in blood glucose concentrations toward or below the fasting levels. However, when insulin production is diminished, blood glucose remains elevated for much longer. Although glucose is an essential substrate for the body's cells, not least because the brain is entirely dependent on glucose as a source of fuel, long-term exposure to elevated blood glucose concentrations is associated with severe damage to the heart, kidneys, and eyes, as well as the nerves in the hands and feet, although it is unclear whether this is a direct effect.

A person's susceptibility to diabetes depends on a combination of intrinsic factors that influence (i) the insulin producing capacity of the pancreatic beta cells, (ii) cellular insulin sensitivity, (iii) the amount of glucose coming from the gut (digestion of food) and liver (gluconeogenesis), and 
(iv) the extent to which glycogen is degraded (glycogenolysis). Thus, T2D is caused by a relative deficiency in insulin action, with the primary cause of this deficiency relating to defect(s) in exogenous insulin production, insulin signaling, and/or the overavailability of glucose. In part because T2D is well established to have strong genetic [3] and lifestyle [4] determinants, many have speculated that the disease is caused by gene-environment interactions [5], with the "environmental" component relating primarily to lifestyle factors such as physical inactivity, poor diet, and obesity.

\section{Brief Overview of the Genetics of T2D}

Evidence that T2D has a strong genetic component came initially from family-based studies, where the observation that diabetes clusters within groups of biologically related individuals led to the quantification of diabetes heritability [3] and familial risk, through which having parents with diabetes was determined to double the risk of T2D [6]. The Botnia Family Study provided seminal evidence of the metabolic consequences of diabetes family history; this study showed that offspring with first-degree diabetic relatives tend to be more obese and insulin resistant and have lower basal metabolic rate [7] and aerobic fitness [8] and are more prone to develop T2D $[8,9]$ than people without a family history of diabetes. These metabolic disturbances are thought to result from defects in skeletal muscle oxidative energy metabolism. For example, insulin resistant, but otherwise healthy, young adults with a positive family history of diabetes [10] are more prone to accumulate intramyocellular lipids, the inorganic phosphate: phosphocreatine ratio in skeletal muscle is lower, and mitochondrial phosphorylation is substantially blunted, compared with persons who are insulin sensitive, regardless of family history.

Quantitative genetics, which exploits information about familial relatedness and disease (or trait) coalescence, has been used to estimate the extent to which a disease or trait is explained by genetic factors. "Broad sense" heritability estimates $(\mathrm{H} 2)$ for T2D reflect the ratio of the total genetic to the total environmental variances explained by these factors for a given phenotype. In conventional quantitative genetic analyses, the genetic and environmental influences on the phenotype are estimated by comparing related and unrelated individuals, while the phenotype is directly measured. There are various factors that may mean that $\mathrm{H} 2$ overestimates the underlying genetic component of a phenotype; these factors include correlations between genotypes and environmental factors and the sharing of environmental factors amongst related individuals. To overcome some of these limitations, methods have been developed that allow the partitioning of genetic $\left(a^{2}\right)$ from shared $\left(c^{2}\right)$ and unshared $\left(e^{2}\right)$ phenotypic variances. The gold-standard design includes studying identical twins separated at birth and reared apart (often called "the adopted twin pair design"). Whilst the latter is more robust to confounding than $\mathrm{H} 2$ estimates, genetic estimates derived using the adopted twin pair design may still be confounded by nongenetic intrauterine environmental factors, which are shared by identical twins but not by unrelated individuals.
For diseases such as T2D and obesity, where intrauterine programing events impact the diseases' etiologies, this source of confounding may lead to an overestimation of the genetic influence on a particular trait. Nevertheless, heritability estimates do help researchers determine whether costly molecular genetic studies of a given trait are justified. In the case of T2D, heritability estimates derived from the Danish Twin Registry have been widely cited [3]. In this study, additive genetic $\left(a^{2}\right)$ factors explained $26 \%$ and shared environmental $\left(c^{2}\right)$ factors explained $41 \%$ of the twin resemblance in diabetes, with unshared environmental factors and model error $\left(e^{2}\right)$ explaining the remainder of the variance.

The search for the specific genetic variants that cause T2D has been underway since the mid-1990s. Linkage studies in families and genetic association studies in cohorts of unrelated individuals have been the predominant approaches used by population geneticists. Although linkage studies have proven highly effective for the detection of rare, highly penetrant genetic loci responsible for diseases such Huntington's and Tay-Sachs, the inherent sample size limitations of family-based studies have rendered linkage scans too small (and thus underpowered) to detect loci for T2D, which are generally more frequent, but convey relatively small effects; even meta-analyses of T2D linkage scans, for example, include $<10,000$ individuals [11], a sample size that is dwarfed by modern genetic association study meta-analyses that approach 100,000 case-control samples [12]. However, these very large sample collections have only recently become available, and genetic association studies conducted prior to 2007 (the point at which genome-wide studies started to gain popularity) were often confined to no more than a few hundred case-control pairs. A very noteworthy exception to the failure of linkage scans in T2D genetics is that of TCF7L2, which was initially identified by fine-mapping a linkage peak at Chromosome 10q25.3 [13]. Importantly, however, the T2D single-nucleotide polymorphism (SNP) that was discovered by fine-mapping the region beneath the linkage peak did not explain the linkage signal, indicating that the discovery of this T2D locus was largely serendipitous. At the time when TCF7L2 was discovered, only two other bona fide T2D loci were known (PPARG Pro12Ala and KCNJ11 E23K). However, the advent of massively parallel, high throughput genotyping technologies (in the form of genomewide association studies [GWAS] and other variations on these arrays including Metabochip and the Exome chip), combined with the availability of very large case-control cohorts, and a willingness of geneticists to work closely together, triggered a quantum leap in the discovery of T2D loci. Indeed, since the discovery of TCF7L2 in 2006 [13], more than 100 independent genetic loci have been discovered and are now reliably associated with T2D [12] or its quantitative metabolic traits (glucose and insulin) [14].

\section{Brief Overview of Lifestyle and T2D Risk}

Family history of a disease implies the presence of genetic risk factors that are shared amongst family members. However, the relationship between established genetic polymorphisms 
and parental history of diabetes is surprisingly weak [15]. One explanation for this apparent anomaly is that diabetespredisposing behaviors, as well as genes, are shared amongst family members. Whilst heritability studies of T2D are often used to underscore the importance genetic factors play in the etiology of the disease, they emphasize to an even greater degree the substantial role environmental risk factors play. Of the many probable environmental determinants of diabetes, obesity stands out as the most strongly established modifiable risk factor. At the point of diagnosis, roughly $80-95 \%$ of European whites with diabetes are overweight or obese [16]. Cohort studies indicate that a standard deviation unit increase in body mass index (BMI: $3.6 \mathrm{~kg} / \mathrm{m}^{2}$ in men, $4.5 \mathrm{~kg} / \mathrm{m}^{2}$ in women) or waist circumference $(10.1 \mathrm{~cm}$ in men, $11.3 \mathrm{~cm}$ in women) equates to approximately a doubling of the hazards of developing T2D in European populations [17]. Perhaps most convincingly, clinical trials, in which participants were randomized to either standard of care or intensive lifestyle interventions, demonstrate that the risk of T2D declines in a manner that is dependent on the degree of weight loss and in the absence of weight loss, there is minimal risk reduction from diet and exercise [18]. It stands to reason, therefore, that risk factors which are causally associated with obesity are also likely to convey risk for T2D, albeit to a lesser extent (because obesity is not an absolute determinant of T2D).

Physical inactivity and sedentary behaviors are important risk factors for a number of complex, noncommunicable diseases such as T2D. Prior to the introduction of insulin, vigorous exercise was frequently prescribed to control blood glucose concentrations in people with diabetes. Studies conducted in the first half of the Twentieth Century sought to elucidate the mechanisms through which exercise lowers blood glucose concentrations in people with diabetes [19]. Studies conducted in the 1960s began to employ techniques that enabled regional and systemic peripheral glucose utilization to be compared during rest and exercise and noted "the necessity for regulation of physical activity in any therapeutic program that is designed to monitor the utilization of extracellular glucose." [20]. However, it was not until the latter half of the Twentieth Century that the specific insulinindependent mechanism of exercise for glucose translocation from the blood into the cell nucleus was identified, with GLUT4 as the key molecule [21].

There is an extensive literature on dietary and nutritional risk factors for T2D. Most of the published evidence in this regard has come from epidemiologic studies. The Nurses' Health Study and the Health Professional's Follow-up Study have been the source of much of the literature on the nutritional epidemiology of T2D in women and men. Studies in these cohorts have shown that high intakes of sugar sweetened beverages [22-25], fruit juice [22], red [26, 27] and processed [28, 29] meats, white rice [30], fish [31], heme iron $[32,33]$, potatoes [34], transfatty acids [35], low carbohydrate [36] and high glycemic load [37-40] diets, and irregular eating patterns [41], and overall poor quality diets [4244] are associated with increased diabetes risk. By contrast, dietary anthocyanins (a flavonoid) [45], whole grains, dietary fiber and brown rice [30, 38, 46-48], zinc [49], vitamin $\mathrm{D}$ and calcium $[48,50]$ magnesium $[48,51]$, potassium $[48]$, caffeinated $[52,53]$ and decaffeinated coffee [52], dairy produce [54], fruit and vegetable [55], light-moderate alcohol [56-58], nuts and peanut butter [59], polyunsaturated fatty acids [35] and vegetable fat [48] intake, and healthy diet patterns combined with other healthful lifestyle behaviors [60] are associated with lower diabetes risk. Not all of these findings are adequately replicated to justify inclusion in the ADA diet recommendations for the prevention of T2D [4]. For example, a recent large European nested case-cohort study of diet and incident T2D called InterAct [61] found that although fruit and vegetable intake per se was not associated with diabetes risk, root vegetables were [62]. The same study showed no association between overall dairy intake and diabetes incidence, but found evidence to support an association of cheese and combined fermented dairy product intake with lower diabetes incidence [63]. Although the Nurses' Health Study and Health Professional's Follow-up Study [31] reported an increased risk of diabetes with higher total fish intake, the InterAct study showed that fatty fish intake was associated with lower diabetes incidence rates (63]. Whereas InterAct [64] and the Health Professional's Followup Study [42] both suggest that Mediterranean-style diets are associated with lower diabetes risk.

The Cohorts for Heart and Aging Research in Genomic Epidemiology (CHARGE) Consortium has also yielded valuable epidemiologic data on the relationships between dietary factors and glucose and insulin concentrations. For example, cross-sectional studies from CHARGE including almost 50,000 white participants from the US and Europe showed strong inverse associations between dietary whole grains [65], total zinc intake [66], and diet pattern [67] with blood glucose and/or insulin concentrations.

In a recent comprehensive review of the nutritional epidemiology literature, Salas-Salvado et al. [68] concluded that intake of fresh vegetables and other plant-based foods, whole grains, pulses and nuts, and reduced intake of red and processed meat, sugar-sweetened foods and beverages, highfat dairy products, and refined grains all appear protective of T2D.

The most recent American Diabetes Association diet guidelines for the prevention and management of T2D focus primarily on diets that lead to maintainable weight loss [4], as clinical trials show that weight loss is the most impactful physiological adaptation that can be safely induced for the prevention of diabetes and other chronic diseases [5, 69]. However, the ADA also acknowledges that even though a range of diets have been shown to reduce body weight in the short term (up to 6 months), the bigger challenge is maintaining long-term weight loss, as short-term successful weight loss is invariably followed by a period of weigh regain. In a randomized controlled trial comparing four different weight loss diets that varied in their composition of fats, carbohydrates, and protein [70], the authors concluded that irrespective of the diets' macronutrient contents, a similar degree of weight loss and weight-regain occurred, and that by the end of the trial ( 2 yrs), the majority of participantshad 
returned to their baseline weights. Studies such as this illustrate the difficulties in maintaining long-term weight loss even in those at high risk of diabetes, despite widespread awareness that weight gain is a major risk factor for the disease. Nevertheless, there are those who are successful in maintaining reduced weight over the long-term; it maybe that molecular biomarkers, such as genotypes, exist can be used to predict a person's susceptibility to weight regain after intentional weight loss; this might help identify those who are likely to require most support in weight loss intervention studies and are hence most prone to develop diabetes.

\section{Genetics of Weight Loss and Weight Regain}

Weight loss and weight gain have a major role in the development of T2D. Thus, many have sought to understand the mechanisms through which these processes occur in anticipation that this might aid in the prevention of diabetes. In a recent study from the Diabetes Prevention Program (DPP) [71], a multiethnic randomized clinical trial of weight loss for diabetes prevention [69], we identified a number of genetic markers that predict weight regain after intentional weight loss through lifestyle modification or metformin treatment. Two of these variants (BDNF rs6265, PPARG Pro12Ala/rs1801282) conveyed effects on weight regain that were statistically significant after adjustment for multiple hypothesis testing and were evident in the entire multiethic cohort and in Non-Hispanic Whites only, mitigating the possibility that confounding by population stratification underlies these effects. Two other variants (TMEM18 rs6548238, KTCD15 rs29941) interacted with treatment modality to affect weight regain. Novel associations with short- and/or long-term weight loss or change in adiposity were also identified for the PPARG rs1801282, NEGR1 rs281575, FTO rs9939609, SH2B1 rs7498665, and MSRA rs7826222 variants.

Although genetic associations with weight loss are biologically informative, the genetic associations with weight regain are probably most clinically relevant, as this information might help target additional support towards persons who struggle most in efforts to maintain reduced weight, thus improving the long-term efficacy of weight-loss interventions. Irrespective of which weight-loss intervention DPP participants were randomized to, variants in NEGR1 and $B D N F$ predicted weight regain in DPP participants. Both genes are expressed within the central nervous system (CNS). The mechanisms that link NEGR1 with obesity are poorly understood. NEGR1 is a cell adhesion molecule that is involved in establishing and remodeling the neural circuit [72] and determining synapse number in hippocampal neurons $[73,74]$. Thus, it is possible that functional variants in NEGR1 may have wide-reaching effects on the development of conditioned traits such as taste, hunger, satiation, and other preference driven aspects of energy balance behaviors [75]. BDNF is expressed in a range of human tissues including brain. BDNF phosphorylates AMP-activated protein kinase (AMPK), a key sensor of cellular energy levels, and acetyl coenzyme A carboxylase-beta (ACCbeta), processes that enhance fatty acid oxidation [76]. By consequence, $B D N F$ transcription and translation increases in myocytes following electrical stimulation, suggesting that $B D N F$ is exercise responsive; it has long been recognized that BDNF protects against neuronal damage inflicted by hypoxic ischemia [77], another process impacting cellular energy metabolism. BDNF transcription and germline mutations have been associated with rare syndromic forms of obesity $[78,79]$, and animal studies indicate may be attributable to hyperphagia caused by disruptions to the appetite and satiety regulating centers of the brain, such as the ventromedial and dorsomedial hypothalamic axes [80-82].

Several loci (FTO rs9939609, TMEM18 rs6548238, BDNF rs6265, KTCD15 rs29941) showed nominally statistically significant treatment-specific effects on rate of weight regain in the entire DPP cohort and in Non-Hispanic Whites only. FTO has been widely studied for its role in energy intake and other aspects of energy metabolism [83-93], but little is known of the mechanisms underlying the relationship of this locus with obesity in humans. The FTO rs9969309 variant is unlikely to be functional owing to its location within an intron, although it may participate in the transcriptional regulation of FTO and neighboring genes. Mice lacking the Fto gene are leaner than wild-type mice owing to increased total energy expenditure and sympathetic activity; spontaneous locomotor activity does not differ in these animals, however, and they are hyperphagic [94]. Elsewhere, the ratio of lean to fat mass in mice harboring a dominant Fto mutation increases with high fat feeding; fat and carbohydrate metabolism genes in white adipose tissue are also overexpressed in these animals [95]. As with the weight loss analyses, we were unable to detect any statistically significant effect mediators of the SNP effects on weight regain.

Almost all of the loci studied here have been associated with an obesity-related trait in recent GWAS meta-analyses [96]. The exception is the PPARG Pro12Ala/rs1801282 variant, which has not featured as a top-ranking variant in GWAS, but may be associated with obesity through interactions with lifestyle factors such as dietary fat intake [97]. We have previously examined this variant in relation to obesity-related traits in the DPP and identified gene-treatment interactions $[98,99]$. It is possible that such interactions mask the main effect of a variant when studied in GWAS [100]. Our findings suggest that the PPARG Pro12Ala/rs1801282 SNP may be of significant clinical interest, as it was associated with larger baseline waist circumference, larger visceral adipose tissue (VAT) area, and with all three longitudinal obesity metrics (greater short-term and long-term weight loss and greater tendency for weight regain) in the full DPP study sample, regardless of treatment group. Nicklas et al. also found that the Pro12 Ala variant was associated with greater weight loss after a 6-month weight-loss intervention and greater regain at 1 year following the absence of continued intervention, noting reductions in the rate of fat oxidation and fat oxidation relative to resting metabolic rate [101]. Interestingly, we found that reductions in adiposity with weight loss were primarily via reductions in subcutaneous (SAT) and not VAT, indicating that genetic variation may influence which fat stores are metabolized and reduced with 
lifestyle or metformin intervention. We found that some loci (NEGRI rs2815752) specifically influenced long-term weight loss outcomes when individuals were assigned to metformin treatment. This information may be helpful when seeking to tailor choices of lifestyle or medication treatments for obesity.

Interestingly, the TMEM18 rs6548238 nonobesogenic allele was protective of weight regain in the lifestyle intervention, but increased the rate of regain in the placebo group, indicating that aspects of the lifestyle interventions, such as caloric restriction and alterations in the pattern of fat intake, may modify the obesogenic effect of the gene, possibly in a ligand-dependent manner.

\section{What is a Gene-Environment Interaction?}

Before proceeding to discuss the evidence base and public health implications of gene-lifestyle interactions, it is important to begin by defining what the concept means in the framework of this review and in other settings. Here, the word "interaction" will be used in a formal statistical sense, where the combined effects of the genetic and environmental (in this case the environmental factors are lifestyle behaviors) exposures are more than additive.

In very simple terms, interaction effects can be described in one of three ways. Figure 1 shows examples of different types of interaction effects for a dichotomous outcome, such as diabetes. The first type is sometimes called a "removable interaction" (Figure 1(a)). In this scenario, the genotype exerts an effect in people who are exposed as well as in those who are not exposed to the environmental risk factor; however, the genetic effect is substantially larger in one environmental exposure group than in the other. Importantly, the scale on which the interaction effect is portrayed is especially important to consider with this type of interaction, as the scale alone may underlie the apparent presence or absence of an interaction effect. The second type of interaction, a "nonremovable, pure interaction," (Figure 1(b)) is characterized by the presence of a genetic effect, which exists only in one of the two environmental exposure groups. In this scenario, the scale is less important to consider than for a removable interaction, although the absolute magnitude of the interaction effect may differ depending on the scale used. The third type of interaction shown here is called a "cross-over" interaction (Figure 1(c)), where a genotype conveys risk of disease in people who are unexposed to the environmental risk factor, but is protective of disease in persons who are exposed to the environmental factor, is probably the rarest, but perhaps most clinically impactful type of interaction. This type of interaction is sometimes called a "nonremovable, cross-over" interaction. In the context of T2D, there are no appropriately replicated examples of cross-over interactions, but in plant genetics, several examples have been documented [102].

\section{Studies Reporting Gene-Lifestyle Interactions in T2D}

Cross-sectional association studies that seek to assess associations or interactions with lifestyle-associated diseases are prone to "labeling" bias, which can differentially affect the accuracy of self-reported lifestyle behaviors in persons with and without a disease diagnosis (or label). For example, because lifestyle is a well-known risk factor for diabetes, people with new onset T2D, when queried about their diet and physical activity levels, may be inclined to overreport consumption of healthy foods and levels of activity, whereas persons who have not been diagnosed with diabetes may report these behaviors more accurately. Thus, cross-sectional studies of lifestyle and T2D are especially prone to bias, particularly when lifestyle exposures are assessed using self-report methods. This caveat applies whether the studies are focused on assessing associations between lifestyle and diabetes or on gene-lifestyle interactions and diabetes. Thus, prospective cohort studies are really required to draw veritable conclusions about the gene-lifestyle interactions and T2D risk, whereas cross-sectional investigations may be sufficient when subclinical diabetes-related traits such as glucose and insulin concentrations are the subject of the interaction analyses.

Only a handful of published prospective cohort studies have reported interactions between genetic and lifestyle factors in relation to T2D. In a recent study from Sweden, Hindy et al. [103] used a cohort of nearly 25,000 initially nondiabetic Swedish adults to assess interactions between dietary fiber and the TCF7L2 rs7903146 variant on T2D incidence. In the 12-year follow-up period, 1,649 diabetes events occurred. The authors reported a nominally statistically significant interaction between the TCF7L2 rs7903146 variant and dietary fiber intake in T2D risk $\left(P_{\text {interaction }}=0.049\right)$, whereby the odds of developing diabetes conveyed by the TCF7L2 variant were lower (OR: 1.24, 95\% CI 1.04, 1.47) in participants within the highest quartile of dietary fiber intake compared with those in the lowest quartile of fiber intake (OR: 1.56, 95\% CI $1.31,1.86)$. In the same Swedish cohort, Sondestedt et al, reported statistically significant interactions between the GIPR rs10423928 variant and dietary carbohydrate and fat intake in relation to T2D incidence; in these analyses, the odds of diabetes conveyed by the TT genotype were lowest in participants in the highest quintile of dietary carbohydrate intake and in the lowest quintile of dietary fat intake.

In a separate study from Sweden (the Malmö Preventive Project) involving more than 16,000 initially nondiabetic adults who were followed for $25 \mathrm{yrs}$ (in which $\sim 2,500$ diabetes events occurred), Brito et al. assessed gene-physical activity interactions for 17 confirmed T2D loci and T2D. The authors identified one interaction effect that withstood Bonferroni correction at the HNF1B locus (rs4430796) [104], in carriers of the low-risk GG genotype, physical activity at baseline was associated with lower rates of diabetes, whereas with each copy of the high-risk A allele, the extent to which physical activity lowered diabetes risk was diminished. The authors also reported interactions between the same variant and physical activity on 2-hour glucose concentrations in 8,860 nondiabetic participants from the same study $\left(P_{\text {interaction }}=\right.$ 0.0009 ). A further two variants (PPARG $\mathrm{rs} 1801282$ and $C D K N 2 A / B$ rs10811661) showed evidence of interactions with physical activity $\left(P_{\text {interaction }}=0.04\right.$ and 0.013 , resp. $)$ on 2-hour blood glucose concentrations, but there was no statistically robust evidence of interaction on incident T2D. 


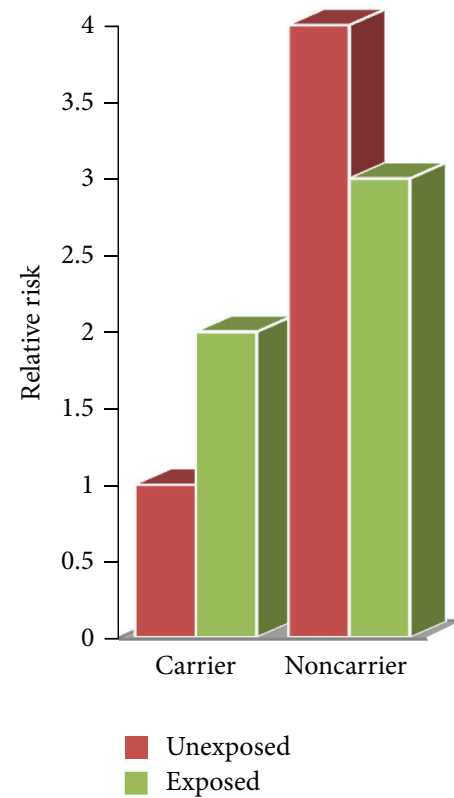

(a)

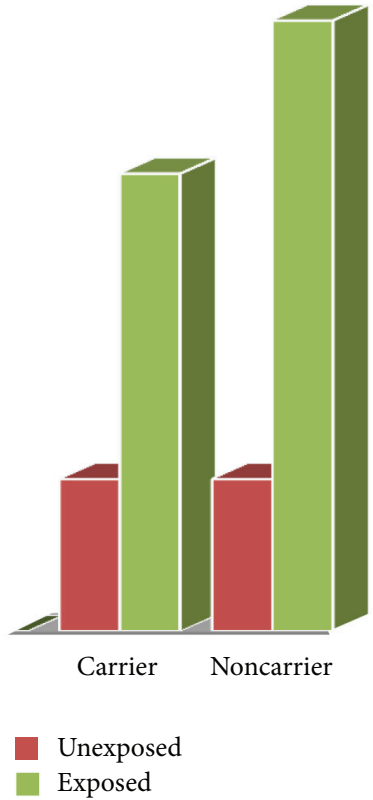

(b)

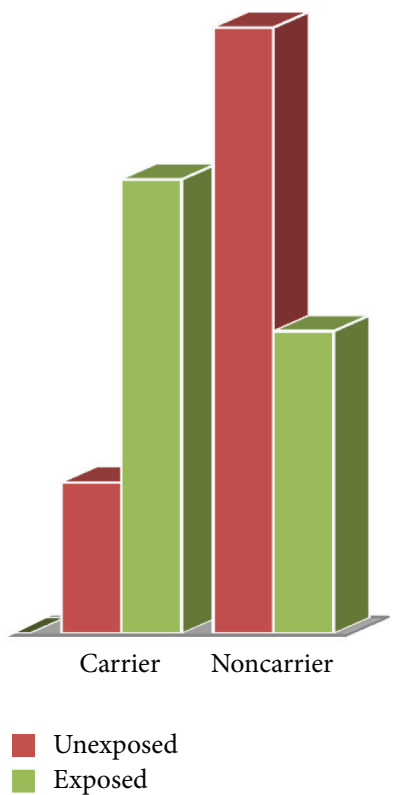

(c)

FIGURE 1: Three different types of interaction effects for a dichotomous outcome, such as diabetes. (a) shows a "removable interaction." In this scenario, the genotype exerts an effect in people who are exposed as well as in those who are not exposed to the environmental risk factor, but larger genetic effect in one environmental exposure group than in the other. (b) shows a "nonremovable, pure interaction," which is characterized by the presence of a genetic effect only in one of the two environmental exposure groups. (c) shows a "cross-over" interaction, where a genotype conveys risk of disease in people who are exposed to the environmental risk factor, but is protective of disease in persons who are unexposed to the same environmental factor.

Several clinical trials have reported gene-lifestyle interactions on diabetes incidence. The majority of these studies have emerged from the DPP, where both biologic candidate genes [105] and those identified through GWAS have been examined. For example, Florez et al. assessed the interaction of the TCF7L2 rs7903146 variant and intensive lifestyle modification (versus placebo control) and found no statistical evidence of a gene-treatment interaction $\left(P_{\text {interaction }}=0.15\right)$ [106]. Mather et al. undertook a comprehensive assessment of common variants within the genes encoding adiponectin $(A D I P O Q)$ and its known receptors (ADIPOR1/2) none of the $A D I P O Q$ variants was directly associated with diabetes incidence, and although two ADIPOR1 variants (rs1342387 and rs12733285) were associated with diabetes incidence these variants did not associate with adiponectin concentrations nor did they differ in their effects across treatment arms [107]. Hivert et al. conducted a comprehensive assessment of genelifestyle interactions in the DPP by examining 34 previously associated T2D loci. The authors concluded that although in aggregate the SNPs were associated with T2D incidence, there was no difference in effect between lifestyle and control arms, strongly suggesting that these variants do not interact with lifestyle to influence diabetes risk $\left(P_{\text {interaction }}>0.05\right)$. In two of the initial DPP genetics studies, Moore et al. [108] reported statistically significant gene-lifestyle interactions between the ENPP1 rs1044498 variant and lifestyle intervention on diabetes incidence $\left(P_{\text {interaction }}=0.03\right)$. Within treatment arm, the Q allele (versus KK homozygotes) was associated with a high hazard ratio $(1.38 ; 95 \% \mathrm{CI}: 1.08-1.76 ; P=0.009)$ than in the placebo arm, whereas this effect was apparently abolished by lifestyle intervention. In a separate analysis, Moore et al. [109] reported an interaction between the $C D K N 2 A / B$ rs10811661 variant and lifestyle (versus placebo control) intervention on diabetes incidence, which although this result is only nominally statistically significant $\left(P_{\text {interaction }}=\right.$ 0.05 ), is directionally consistent with the gene-physical activity interaction reported by Brito et al. [104] (see above).

Thus, while a few studies have provided tentative evidence of gene-lifestyle interactions in T2D, some might argue that few or none have been adequately replicated. It remains implausible that gene-lifestyle interactions do not exist, owing to compelling ecological evidence from ethic comparisons and migration studies, yet in the absence of compelling empirical evidence, it is impossible to draw conclusions about the clinical and public health relevance of specific genelifestyle interactions. Future studies that are both larger in scale and which focus on lower frequency gene variants may yield more promising results. It is also possible that the common strategy of focusing primarily on gene variants that have emerged from GWAS of T2D has hindered the discovery of variants that interact with lifestyle; the reasons for why this may be discussed in detail elsewhere [110].

\section{Conclusions}

T2D affects almost all developed and developing societies. The major risk factor is abdominal obesity, yet not all those who are obese develop the disease, and not all of those 
who are at high risk of diabetes remain disease-free by losing weight. The variation in susceptibility to diabetes given different lifestyles is widely believed to be driven by gene variants that interact with environmental factors, yet evidence supporting this view is deficient. Given that it remains highly plausible that gene-environment interactions cause diabetes, and that veritable examples of geneenvironment interactions are commonplace in murine and plant models, one should carefully consider why current approaches to studying gene-lifestyle interactions in human diabetes have generally failed to provide concrete support for such relationships. One explanation may be that for common variants, interaction effects are small in magnitude and given the low level of precision with which lifestyle risk factors are generally measured in epidemiology, the sample sizes and mathematical approaches used in studies of interaction afford insufficient statistical power. Indeed, these explanations have fueled a new era of gene-lifestyle interaction studies that are focused on much larger cohort collections and more sophisticated analytical approaches than seen before [111]. It is possible that such studies will yield credible evidence of gene-lifestyle interactions in diabetes and provide clinicallyrelevant information for the prevention or treatment of this devastating disease.

\section{Acknowledgments}

This paper is entirely the author's own work unless indicated otherwise. The author thanks Shafqat Ahmad with valuable editorial assistance. The author is supported by Grants from the Swedish Research Council, the Swedish Diabetes Association, Novo Nordisk, the Swedish Heart-Lung Foundation, the European Union, the National Institutes of Health, and Exodiab.

\section{References}

[1] J. E. Shaw, R. A. Sicree, and P. Z. Zimmet, "Global estimates of the prevalence of diabetes for 2010 and 2030," Diabetes Research and Clinical Practice, vol. 87, no. 1, pp. 4-14, 2010.

[2] A. American Diabetes, "Diagnosis and classification of diabetes mellitus," Diabetes Care, vol. 35, supplement 1, pp. S64-S71, 2012.

[3] P. Poulsen, K. Ohm Kyvik, A. Vaag, and H. Beck-Nielsen, "Heritability of type II (non-insulin-dependent) diabetes mellitus and abnormal glucose tolerance-a population-based twin study," Diabetologia, vol. 42, no. 2, pp. 139-145, 1999.

[4] A. American Diabetes, J. P. Bantle, J. Wylie-Rosett et al., "Nutrition recommendations and interventions for diabetes: a position statement of the American Diabetes Association," Diabetes Care, vol. 31, suppelement 1, pp. S61-S78, 2008.

[5] J. Tuomilehto, J. Lindström, J. G. Eriksson et al., "Prevention of type 2 diabetes mellitus by changes in lifestyle among subjects with impaired glucose tolerance," The New England Journal of Medicine, vol. 344, no. 18, pp. 1343-1350, 2001.

[6] P. W. F. Wilson, J. B. Meigs, L. Sullivan, C. S. Fox, D. M. Nathan, and R. B. D'Agostino, "Prediction of incident diabetes mellitus in middle-aged adults: the framingham offspring study," Archives of Internal Medicine, vol. 167, no. 10, pp. 1068-1074, 2007.
[7] L. Groop, C. Forsblom, M. Lehtovirta et al., "Metabolic consequences of a family history of NIDDM (the Botnia study): evidence for sex-specific parental effects," Diabetes, vol. 45, no. 11, pp. 1585-1593, 1996.

[8] B. Isomaa, B. Forsén, K. Lahti et al., "A family history of diabetes is associated with reduced physical fitness in the Prevalence, Prediction and Prevention of Diabetes (PPP)-Botnia study," Diabetologia, vol. 53, no. 8, pp. 1709-1713, 2010.

[9] V. Lyssenko, P. Almgren, D. Anevski et al., "Predictors of and longitudinal changes in insulin sensitivity and secretion preceding onset of type 2 diabetes," Diabetes, vol. 54, no. 1, pp. 166-174, 2005.

[10] K. F. Petersen, S. Dufour, D. Befroy, R. Garcia, and G. I. Shulman, "Impaired Mitochondrial Activity in the InsulinResistant Offspring of Patients with Type 2 Diabetes," The New England Journal of Medicine, vol. 350, no. 7, pp. 664-671, 2004.

[11] W. Guan, A. Pluzhnikov, N. J. Cox, and M. Boehnke, "Metaanalysis of 23 type 2 diabetes linkage studies from the international type 2 diabetes linkage analysis consortium," Human Heredity, vol. 66, no. 1, pp. 35-49, 2008.

[12] The Diabetes Genetics Replication and Meta-analysis (DIAGRAM) Consortium, C. Meta-analysis, A. P. Morris et al., "Large-scale association analysis provides insights into the genetic architecture and pathophysiology of type 2 diabetes," Nature Genetics, vol. 44, no. 9, pp. 981-990, 2012.

[13] S. F. A. Grant, G. Thorleifsson, I. Reynisdottir et al., "Variant of transcription factor 7-like 2 (TCF7L2) gene confers risk of type 2 diabetes," Nature Genetics, vol. 38, no. 3, pp. 320-323, 2006.

[14] R. A. Scott, V. Lagou, R. P. Welch, E. Wheeler, M. E. Montasser, J. Luan et al., "Large-scale association analyses identify new loci influencing glycemic traits and provide insight into the underlying biological pathways," Nature Genetics, vol. 44, no. 9, pp. 991-1005, 2012.

[15] J. L. Vassy, P. Shrader, A. Jonsson et al., "Association between parental history of diabetes and type 2 diabetes genetic risk scores in the PPP-Botnia and Framingham Offspring Studies," Diabetes Research and Clinical Practice, vol. 93, no. 2, pp. e76-e79, 2011.

[16] A. Astrup, "Healthy lifestyles in Europe: prevention of obesity and type II diabetes by diet and physical activity," Public Health Nutrition, vol. 4, no. 2, pp. 499-515, 2001.

[17] C. InterAct, C. Langenberg, S. J. Sharp, M. B. Schulze, O. Rolandsson, K. Overvad et al., "Long-term risk of incident type 2 diabetes and measures of overall and regional obesity: the EPIC-InterAct case-cohort study," PLoS Medicine, vol. 9, no. 6, Article ID e1001230, 2012.

[18] R. F. Hamman, R. R. Wing, S. L. Edelstein et al., "Effect of weight loss with lifestyle intervention on risk of diabetes," Diabetes Care, vol. 29, no. 9, pp. 2102-2107, 2006.

[19] R. D. Lawrence, "The effect of exercise on insulin action in diabetes," British Medical Journal, vol. 1, no. 3406, pp. 648-650, 1926.

[20] C. A. Sanders, G. E. Levinson, W. H. Abelmann, and N. Freinkel, "Effect of exercise on the peripheral utilization of glucose in man," The New England Journal of Medicine, vol. 271, pp. 220-225, 1964.

[21] K. J. Rodnick, R. C. Piper, J. W. Slot, and D. E. James, "Interaction of insulin and exercise on glucose transport in muscle," Diabetes Care, vol. 15, no. 11, pp. 1679-1689, 1992. 
[22] A. Pan, V. S. Malik, M. B. Schulze, J. E. Manson, W. C. Willett, and F. B. Hu, "Plain-water intake and risk of type 2 diabetes in young and middle-aged women," The The American Journal of Clinical Nutrition, vol. 95, no. 6, pp. 1454-1460, 2012.

[23] L. de Koning, V. S. Malik, E. B. Rimm, W. C. Willett, and F. B. Hu, "Sugar-sweetened and artificially sweetened beverage consumption and risk of type 2 diabetes in men," The American Journal of Clinical Nutrition, vol. 93, no. 6, pp. 1321-1327, 2011.

[24] V. S. Malik, B. M. Popkin, G. A. Bray, J. P. Després, W. C. Willett, and F. B. Hu, "Sugar-sweetened beverages and risk of metabolic syndrome and type 2 diabetes: a meta-analysis," Diabetes Care, vol. 33, no. 11, pp. 2477-2483, 2010.

[25] M. B. Schulze, J. E. Manson, D. S. Ludwig et al., "Sugarsweetened beverages, weight gain, and incidence of type 2 diabetes in young and middle-aged women," The Journal of the American Medical Association, vol. 292, no. 8, pp. 927-934, 2004.

[26] A. Pan, Q. Sun, A. M. Bernstein, M. B. Schulze, J. E. Manson, W. C. Willett et al., "Red meat consumption and risk of type 2 diabetes: 3 cohorts of US adults and an updated meta-analysis," The The American Journal of Clinical Nutrition, vol. 94, no. 4, pp. 1088-1096, 2011.

[27] T. T. Fung, M. Schulze, J. E. Manson, W. C. Willett, and F. B. Hu, "Dietary patterns, meat intake, and the risk of type 2 diabetes in women," Archives of Internal Medicine, vol. 164, no. 20, pp. 2235-2240, 2004.

[28] M. B. Schulze, J. E. Manson, W. C. Willett, and F. B. Hu, "Processed meat intake and incidence of Type 2 diabetes in younger and middle-aged women," Diabetologia, vol. 46, no. 11, pp. 1465-1473, 2003.

[29] R. M. van Dam, W. C. Willett, E. B. Rimm, M. J. Stampfer, and F. B. Hu, "Dietary fat and meat intake in relation to risk of type 2 diabetes in men," Diabetes Care, vol. 25, no. 3, pp. 417-424, 2002.

[30] Q. Sun, D. Spiegelman, R. M. Van Dam et al., "White rice, brown rice, and risk of type 2 diabetes in US men and women," Archives of Internal Medicine, vol. 170, no. 11, pp. 961-969, 2010.

[31] M. Kaushik, D. Mozaffarian, D. Spiegelman, J. E. Manson, W. C. Willett, and F. B. Hu, "Long-chain omega-3 fatty acids, fish intake, and the risk of type 2 diabetes mellitus," The American Journal of Clinical Nutrition, vol. 90, no. 3, pp. 613-620, 2009.

[32] S. Rajpathak, J. Ma, J. Manson, W. C. Willett, and F. B. Hu, "Iron intake and the risk of type 2 diabetes in women: a prospective cohort study," Diabetes Care, vol. 29, no. 6, pp. 1370-1376, 2006.

[33] R. Jiang, J. Ma, A. Ascherio, M. J. Stampfer, W. C. Willett, and F. B. Hu, "Dietary iron intake and blood donations in relation to risk of type 2 diabetes in men: a prospective cohort study," The American Journal of Clinical Nutrition, vol. 79, no. 1, pp. 70-75, 2004.

[34] T. L. Halton, W. C. Willett, S. Liu, J. E. Manson, M. J. Stampfer, and F. B. Hu, "Potato and french fry consumption and risk of type 2 diabetes in women," The American Journal of Clinical Nutrition, vol. 83, no. 2, pp. 284-290, 2006.

[35] J. Salmerón, F. B. Hu, J. E. Manson et al., "Dietary fat intake and risk of type 2 diabetes in women," The American Journal of Clinical Nutrition, vol. 73, no. 6, pp. 1019-1026, 2001.

[36] L. de Koning, T. T. Fung, X. Liao et al., "Low-carbohydrate diet scores and risk of type 2 diabetes in men," The American Journal of Clinical Nutrition, vol. 93, no. 4, pp. 844-850, 2011.
[37] R. A. Mekary, E. B. Rimm, E. Giovannucci et al., "Joint association of glycemic load and alcohol intake with type 2 diabetes incidence in women," The The American Journal of Clinical Nutrition, vol. 94, no. 6, pp. 1525-1532, 2011.

[38] M. B. Schulze, S. Liu, E. B. Rimm, J. E. Manson, W. C. Willett, and F. B. Hu, "Glycemic index, glycemic load, and dietary fiber intake and incidence of type 2 diabetes in younger and middleaged women," The American Journal of Clinical Nutrition, vol. 80, no. 2, pp. 348-356, 2004.

[39] J. Salmerón, A. Ascherio, E. B. Rimm et al., "Dietary fiber, glycemic load, and risk of NIDDM in men," Diabetes Care, vol. 20, no. 4, pp. 545-550, 1997.

[40] J. Salmerón, J. E. Manson, M. J. Stampfer, G. A. Colditz, A. L. Wing, and W. C. Willett, "Dietary fiber, glycemic load, and risk of non-insulin-dependent diabetes mellitus in women," The Journal of the American Medical Association, vol. 277, no. 6, pp. 472-477, 1997.

[41] R. A. Mekary, E. Giovannucci, W. C. Willett, R. M. van Dam, and $\mathrm{F}$. B. Hu, "Eating patterns and type 2 diabetes risk in men: breakfast omission, eating frequency, and snacking," The The American Journal of Clinical Nutrition, vol. 95, no. 5, pp. 1182-1189, 2012.

[42] L. de Koning, S. E. Chiuve, T. T. Fung, W. C. Willett, E. B. Rimm, and F. B. Hu, "Diet-quality scores and the risk of type 2 diabetes in men," Diabetes Care, vol. 34, no. 5, pp. 1150-1156, 2011.

[43] M. B. Schulze, K. Hoffmann, J. E. Manson et al., "Dietary pattern, inflammation, and incidence of type 2 diabetes in women," The American Journal of Clinical Nutrition, vol. 82, no. 3, pp. 675-684, 2005.

[44] R. M. van Dam, E. B. Rimm, W. C. Willett, M. J. Stampfer, and F. B. Hu, "Dietary patterns and risk for type 2 diabetes mellitus in U.S. men," Annals of Internal Medicine, vol. 136, no. 3, pp. 201-209, 2002.

[45] N. M. Wedick, A. Pan, A. Cassidy, E. B. Rimm, L. Sampson, B. Rosner et al., "Dietary flavonoid intakes and risk of type 2 diabetes in US men and women," The The American Journal of Clinical Nutrition, vol. 95, no. 4, pp. 925-933, 2012.

[46] T. T. Fung, F. B. Hu, M. A. Pereira et al., "Whole-grain intake and the risk of type 2 diabetes: a prospective study in men," The American Journal of Clinical Nutrition, vol. 76, no. 3, pp. 535-540, 2002.

[47] S. Liu, J. E. Manson, M. J. Stamfer et al., "A prospective study of whole-grain intake and risk of type 2 diabetes mellitus in US women," American Journal of Public Health, vol. 90, no. 9, pp. 1409-1415, 2000.

[48] G. A. Colditz, J. E. Manson, M. J. Stampfer, B. Rosner, W. C. Willett, and F. E. Speizer, "Diet and risk of clinical diabetes in women," The American Journal of Clinical Nutrition, vol. 55, no. 5, pp. 1018-1023, 1992.

[49] Q. Sun, R. M. van Dam, W. C. Willett, and F. B. Hu, "Prospective study of zinc intake and risk of type 2 diabetes in women," Diabetes Care, vol. 32, no. 4, pp. 629-634, 2009.

[50] A. G. Pittas, B. Dawson-Hughes, T. Li et al., "Vitamin D and calcium intake in relation to type 2 diabetes in women," Diabetes Care, vol. 29, no. 3, pp. 650-656, 2006.

[51] R. Lopez-Ridaura, W. C. Willett, E. B. Rimm et al., "Magnesium intake and risk of type 2 diabetes in men and women," Diabetes Care, vol. 27, no. 1, pp. 134-140, 2004. 
[52] R. M. van Dam, W. C. Willett, J. E. Manson, and F. B. Hu, "Coffee, caffeine, and risk of type 2 diabetes: a prospective cohort study in younger and middle-aged U.S. women," Diabetes Care, vol. 29, no. 2, pp. 398-403, 2006.

[53] E. Salazar-Martinez, W. C. Willett, A. Ascherio et al., "Coffee consumption and risk for type 2 diabetes mellitus," Annals of Internal Medicine, vol. 140, no. 1, pp. 1-8, 2004.

[54] H. K. Choi, W. C. Willett, M. J. Stampfer, E. Rimm, and F. B. Hu, "Dairy consumption and risk of type 2 diabetes mellitus in men: a prospective study," Archives of Internal Medicine, vol. 165, no. 9, pp. 997-1003, 2005.

[55] S. Liu, M. Serdula, S. J. Janket et al., "A prospective study of fruit and vegetable intake and the risk of type 2 diabetes in women," Diabetes Care, vol. 27, no. 12, pp. 2993-2996, 2004.

[56] S. G. Wannamethee, C. A. Camargo, J. E. Manson, W. C. Willett, and E. B. Rimm, "Alcohol drinking patterns and risk of type 2 diabetes mellitus among younger women," Archives of Internal Medicine, vol. 163, no. 11, pp. 1329-1336, 2003.

[57] K. M. Conigrave, B. F. Hu, C. A. Camargo, M. J. Stampfer, W. C. Willett, and E. B. Rimm, "A prospective study of drinking patterns in relation to risk of type 2 diabetes among men," Diabetes, vol. 50, no. 10, pp. 2390-2395, 2001.

[58] E. B. Rimm, J. Chan, M. J. Stampfer, G. A. Colditz, W. C. Willett, and R. E. Laporte, "Prospective study of cigarette smoking, alcohol use, and the risk of diabetes in men," British Medical Journal, vol. 310, no. 6979, pp. 555-559, 1995.

[59] R. Jiang, J. E. Manson, M. J. Stampfer, S. Liu, W. C. Willett, and F. B. Hu, "Nut and peanut butter consumption and risk of type 2 diabetes in women," The Journal of the American Medical Association, vol. 288, no. 20, pp. 2554-2560, 2002.

[60] F. B. Hu, J. E. Manson, M. J. Stampfer et al., "Diet, lifestyle, and the risk of type 2 diabetes mellitus in women," The New England Journal of Medicine, vol. 345, no. 11, pp. 790-797, 2001.

[61] C. InterAct, "Physical activity reduces the risk of incident type 2 diabetes in general and in abdominally lean and obese men and women: the EPIC-InterAct Study," Diabetologia, vol. 55, no. 7, pp. 1944-1952, 2012.

[62] A. J. Cooper, N. G. Forouhi, Z. Ye, B. Buijsse, L. Arriola, B. Balkau et al., "Fruit and vegetable intake and type 2 diabetes: EPIC-InterAct prospective study and meta-analysis," European Journal of Clinical Nutrition, vol. 66, no. 10, pp. 1082-1092, 2012.

[63] I. Sluijs, N. G. Forouhi, J. W. Beulens, Y. T. van der Schouw, C. Agnoli, L. Arriola et al., "The amount and type of dairy product intake and incident type 2 diabetes: results from the EPICInterAct Study," The The American Journal of Clinical Nutrition, vol. 96, no. 2, pp. 382-390, 2012.

[64] C. InterAct, D. Romaguera, M. Guevara et al., "Mediterranean diet and type 2 diabetes risk in the European Prospective Investigation into Cancer and Nutrition (EPIC) study: the InterAct project," Diabetes Care, vol. 34, no. 9, pp. 1913-1918, 2011.

[65] J. A. Nettleton, N. M. McKeown, S. Kanoni et al., "Interactions of dietary whole-grain intake with fasting glucose- and insulinrelated genetic loci in individuals of European descent: a metaanalysis of 14 cohort studies," Diabetes Care, vol. 33, no. 12, pp. 2684-2691, 2010.
[66] S. Kanoni, J. A. Nettleton, M. F. Hivert, Z. Ye, F. J. van Rooij, D. Shungin et al., "Total zinc intake may modify the glucoseraising effect of a zinc transporter (SLC30A8) variant: a 14cohort meta-analysis," Diabetes, vol. 60, no. 9, pp. 2407-2416, 2011.

[67] J. A. Nettleton HM-F, R. N. Lemaitre, N. M. McKeown et al., "A 15-cohort meta-analysis shows inverse associations between healthy diet and fasting glucose and insulin and no evidence of modification by multiple loci associated with glucose homeostasis," American Journal of Epidemiology. In press.

[68] J. Salas-Salvado, M. A. Martinez-Gonzalez, M. Bullo, and E. Ros, "The role of diet in the prevention of type 2 diabetes. Nutrition, metabolism, and cardiovascular diseases," Nutrition, Metabolism and Cardiovascular Diseases, vol. 21, supplement 2, pp. B32-B48, 2011.

[69] W. C. Knowler, E. Barrett-Connor, S. E. Fowler et al., "Reduction in the incidence of type 2 diabetes with lifestyle intervention or metformin," The New England Journal of Medicine, vol. 346, no. 6, pp. 393-403, 2002.

[70] F. M. Sacks, G. A. Bray, V. J. Carey et al., "The New England Journal of Medicine: comparison of weight-loss diets with different compositions of fat, protein, and carbohydrates," The New England Journal of Medicine, vol. 360, no. 9, pp. 859-873, 2009.

[71] L. M. Delahanty, Q. Pan, K. A. Jablonski, K. E. Watson, J. M. McCaffery, A. Shuldiner et al., "Genetic predictors of weight loss and weight regain after intensive lifestyle modification, metformin treatment, or standard care in the Diabetes Prevention Program," Diabetes Care, vol. 35, no. 2, pp. 363-366, 2012.

[72] N. Funatsu, S. Miyata, H. Kumanogoh et al., "Characterization of a novel rat brain glycosylphosphatidylinositol- anchored protein (Kilon), a member of the IgLON cell adhesion molecule family," The Journal of Biological Chemistry, vol. 274, no. 12, pp. 8224-8230, 1999.

[73] T. Hashimoto, S. Maekawa, and S. Miyata, "IgLON cell adhesion molecules regulate synaptogenesis in hippocampal neurons," Cell Biochemistry and Function, vol. 27, no. 7, pp. 496-498, 2009.

[74] T. Hashimoto, M. Yamada, S. Maekawa, T. Nakashima, and S. Miyata, "IgLON cell adhesion molecule Kilon is a crucial modulator for synapse number in hippocampal neurons," Brain Research, vol. 1224, pp. 1-11, 2008.

[75] T. L. Davidson, S. E. Kanoski, L. A. Schier, D. J. Clegg, and S. C. Benoit, "A potential role for the hippocampus in energy intake and body weight regulation," Current Opinion in Pharmacology, vol. 7, no. 6, pp. 613-616, 2007.

[76] B. K. Pedersen, M. Pedersen, K. S. Krabbe, H. Bruunsgaard, V. B. Matthews, and M. A. Febbraio, "Role of exercise-induced brain-derived neurotrophic factor production in the regulation of energy homeostasis in mammals: experimental PhysiologyHot Topic Review," Experimental Physiology, vol. 94, no. 12, pp. 1153-1160, 2009.

[77] B. H. Han and D. M. Holtzman, "BDNF protects the neonatal brain from hypoxic-ischemic injury in vivo via the ERK pathway," Journal of Neuroscience, vol. 20, no. 15, pp. 5775-5781, 2000.

[78] J. C. Han, M. J. Muehlbauer, H. N. Cui, C. B. Newgard, and A. M. Haqq, "Lower brain-derived neurotrophic factor in patients with Prader-Willi syndrome compared to obese and 
lean control subjects," The Journal of Clinical Endocrinology and Metabolism, vol. 95, no. 7, pp. 3532-3536, 2010.

[79] J. C. Han, Q. R. Liu, M. Jones et al., "Brain-derived neurotrophic factor and obesity in the WAGR syndrome," The New England Journal of Medicine, vol. 359, no. 9, pp. 918-927, 2008.

[80] J. W. Cordeira, L. Frank, M. Sena-Esteves, E. N. Pothos, and M. Rios, "Brain-derived neurotrophic factor regulates hedonic feeding by acting on the mesolimbic dopamine system," Journal of Neuroscience, vol. 30, no. 7, pp. 2533-2541, 2010.

[81] M. S. Byerly, J. Simon, E. Lebihan-Duval, M. J. Duclos, L. A. Cogburn, and T. E. Porter, "Effects of BDNF, T3, and corticosterone on expression of the hypothalamic obesity gene network in vivo and in vitro," American Journal of Physiology, vol. 296, no. 4, pp. R1180-R1189, 2009.

[82] T. J. Unger, G. A. Calderon, L. C. Bradley, M. Sena-Esteves, and M. Rios, "Selective deletion of Bdnf in the ventromedial and dorsomedial hypothalamus of adult mice results in hyperphagic behavior and obesity," Journal of Neuroscience, vol. 27, no. 52, pp. 14265-14274, 2007.

[83] C. H. Andreasen, K. L. Stender-Petersen, M. S. Mogensen et al., "Low physical activity accentuates the effect of the FTO rs9939609 polymorphism on body fat accumulation," Diabetes, vol. 57, no. 1, pp. 95-101, 2008.

[84] S. Cauchi, F. Stutzmann, C. Cavalcanti-Proença et al., "Combined effects of MC4R and FTO common genetic variants on obesity in European general populations," Journal of Molecular Medicine, vol. 87, no. 5, pp. 537-546, 2009.

[85] A. Jonsson, F. Renström, V. Lyssenko et al., "Assessing the effect of interaction between an FTO variant (rs9939609) and physical activity on obesity in 15,925 Swedish and 2,511 Finnish adults," Diabetologia, vol. 52, no. 7, pp. 1334-1338, 2009.

[86] T. J. Lappalainen, A. M. Tolppanen, M. Kolehmainen et al., "The common variant in the FTO gene did not modify the effect of lifestyle changes on body weight: the finnish diabetes prevention study," Obesity, vol. 17, no. 4, pp. 832-836, 2009.

[87] E. T. Liem, J. M. Vonk, P. J. J. Sauer et al., "Influence of common variants near INSIG2, in FTO, and near MC4R genes on overweight and the metabolic profile in adolescence: the TRAILS (TRacking Adolescents' Individual Lives Survey) Study," The American Journal of Clinical Nutrition, vol. 91, no. 2, pp. 321-328, 2010.

[88] E. Rampersaud, B. D. Mitchell, T. I. Pollin et al., "Physical activity and the association of common FTO gene variants with body mass index and obesity," Archives of Internal Medicine, vol. 168, no. 16, pp. 1791-1797, 2008.

[89] E. Sonestedt, C. Roos, B. Gullberg, U. Ericson, E. Wirfält, and M. Orho-Melander, "Fat and carbohydrate intake modify the association between genetic variation in the FTO genotype and obesity," The American Journal of Clinical Nutrition, vol. 90, no. 5, pp. 1418-1425, 2009.

[90] J. T. Tan, R. Dorajoo, M. Seielstad et al., "FTO variants are associated with obesity in the chinese and malay populations in Singapore," Diabetes, vol. 57, no. 10, pp. 2851-2857, 2008.

[91] K. S. Vimaleswaran, S. Li, J. H. Zhao et al., "Physical activity attenuates the body mass index-increasing influence of genetic variation in the FTO gene," The American Journal of Clinical Nutrition, vol. 90, no. 2, pp. 425-428, 2009.
[92] T. Rankinen, T. Rice, M. Teran-Garcia, D. C. Rao, and C. Bouchard, "FTO genotype is associated with exercise traininginduced changes in body composition," Obesity, vol. 18, no. 2, pp. 322-326, 2010.

[93] C. Holzapfel, H. Grallert, C. Huth et al., "Genes and lifestyle factors in obesity: results from 12462 subjects from MONICA/KORA," International Journal of Obesity, vol. 34, no. 10, pp. 1538-1545, 2010.

[94] J. Fischer, L. Koch, C. Emmerling et al., "Inactivation of the Fto gene protects from obesity," Nature, vol. 458, no. 7240, pp. 894-898, 2009.

[95] C. Church, S. Lee, E. A. L. Bagg et al., "A mouse model for the metabolic effects of the human fat mass and obesity associated FTO gene," PLoS Genetics, vol. 5, no. 8, Article ID e1000599, 2009.

[96] E. K. Speliotes, C. J. Willer, S. I. Berndt, K. L. Monda, G. Thorleifsson, A. U. Jackson et al., "Association analyses of 249, 796 individuals reveal 18 new loci associated with body mass index," Nature Genetics, vol. 42, no. 11, pp. 937-948, 2010.

[97] P. W. Franks, J. L. Mesa, A. H. Harding, and N. J. Wareham, "Gene-lifestyle interaction on risk of type 2 diabetes," Nutrition, Metabolism and Cardiovascular Diseases, vol. 17, no. 2, pp. 104-124, 2007.

[98] P. W. Franks, K. A. Jablonski, L. Delahanty et al., "The Pro12Ala variant at the peroxisome proliferator-activated receptor $\gamma$ gene and change in obesity-related traits in the Diabetes Prevention Program," Diabetologia, vol. 50, no. 12, pp. 2451-2460, 2007.

[99] J. C. Florez, K. A. Jablonski, M. W. Sun et al., "Effects of the type 2 diabetes-associated PPARG P12A polymorphism on progression to diabetes and response to troglitazone," The Journal of Clinical Endocrinology and Metabolism, vol. 92, no. 4, pp. 1502-1509, 2007.

[100] A. K. Manning, M. LaValley, C. T. Liu et al., "Meta-analysis of gene-environment interaction: joint estimation of SNP and SNP $\times$ environment regression coefficients," Genetic Epidemiology, vol. 35, no. 1, pp. 11-18, 2011.

[101] B. J. Nicklas, E. F. C. Van Rossum, D. M. Berman, A. S. Ryan, K. E. Dennis, and A. R. Shuldiner, "Genetic variation in the peroxisome proliferator-activated receptor- $\gamma 2$ gene (Pro12Ala) affects metabolic responses to weight loss and subsequent weight regain," Diabetes, vol. 50, no. 9, pp. 2172-2176, 2001.

[102] R. J. Baker, "Crossover genotype-environment interaction in spring wheat," in Genotype-by-Environment Interaction and Plant Breeding, M. S. Kang, Ed., Louisiana State University, Agriculture Con, Baton Rouge, La, USA, 1988.

[103] G. Hindy, E. Sonestedt, U. Ericson, X. J. Jing, Y. Zhou, O. Hansson et al., "Role of TCF7L2 risk variant and dietary fibre intake on incident type 2 diabetes," Diabetologia, vol. 55, no. 10, pp. 2646-2654, 2012.

[104] E. C. Brito, V. Lyssenko, F. Renström et al., "Previously associated type 2 diabetes variants may interact with physical activity to modify the risk of impaired glucose regulation and type 2 diabetes: a study of 16,003 Swedish adults," Diabetes, vol. 58, no. 6, pp. 1411-1418, 2009.

[105] K. A. Jablonski, J. B. McAteer, P. I. W. de Bakker et al., "Common variants in 40 genes assessed for diabetes incidence and response to metformin and lifestyle intervention in the diabetes prevention program," Diabetes, vol. 59, no. 10, pp. 2672-2681, 2010. 
[106] J. C. Florez, K. A. Jablonski, N. Bayley et al., "TCF7L2 polymorphisms and progression to diabetes in the Diabetes Prevention Program," The New England Journal of Medicine, vol. 355, no. 3, pp. 241-250, 2006.

[107] K. J. Mather, C. A. Christophi, K. A. Jablonski et al., "Common variants in genes encoding adiponectin (ADIPOQ) and its receptors (ADIPOR1/2), adiponectin concentrations, and diabetes incidence in the Diabetes PreventionProgram," Diabetic Medicine. In press.

[108] A. F. Moore, K. A. Jablonski, C. C. Mason et al., "The association of ENPP1 K121Q with diabetes incidence is abolished by lifestyle modification in the diabetes prevention program," The Journal of Clinical Endocrinology and Metabolism, vol. 94, no. 2, pp. 449-455, 2009.

[109] A. F. Moore, K. A. Jablonski, J. B. McAteer et al., "Extension of type 2 diabetes genome-wide association scan results in the diabetes prevention program," Diabetes, vol. 57, no. 9, pp. 2503-2510, 2008.

[110] P. W. Franks, "Gene x environment interactions in type 2 diabetes," Current Diabetes Reports, vol. 11, no. 6, pp. 552-561, 2011.

[111] A. K. Manning, M. F. Hivert, R. A. Scott, J. L. Grimsby, N. Bouatia-Naji, H. Chen et al., "A genome-wide approach accounting for body mass index identifies genetic variants influencing fasting glycemic traits and insulin resistance," Nature Genetics, vol. 44, no. 6, pp. 659-669, 2012. 


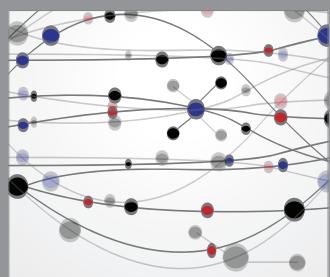

The Scientific World Journal
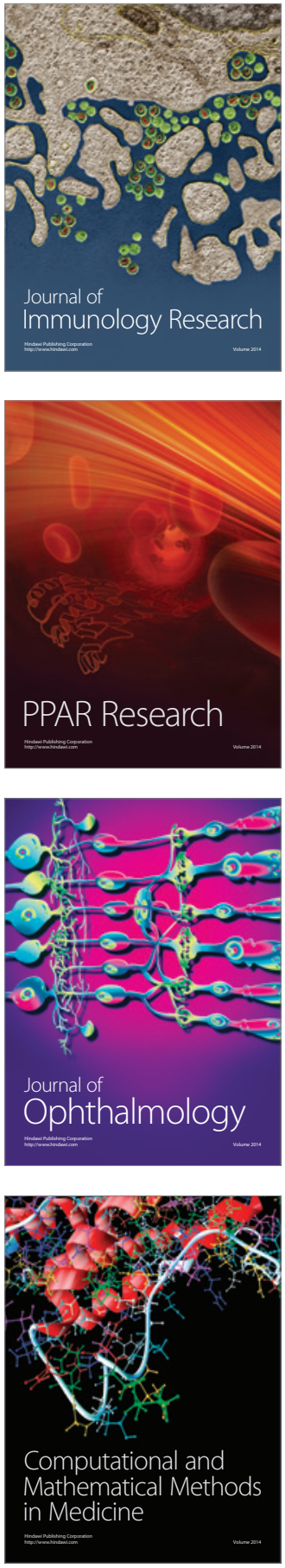

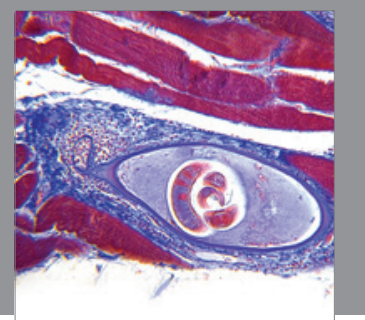

Gastroenterology

Research and Practice
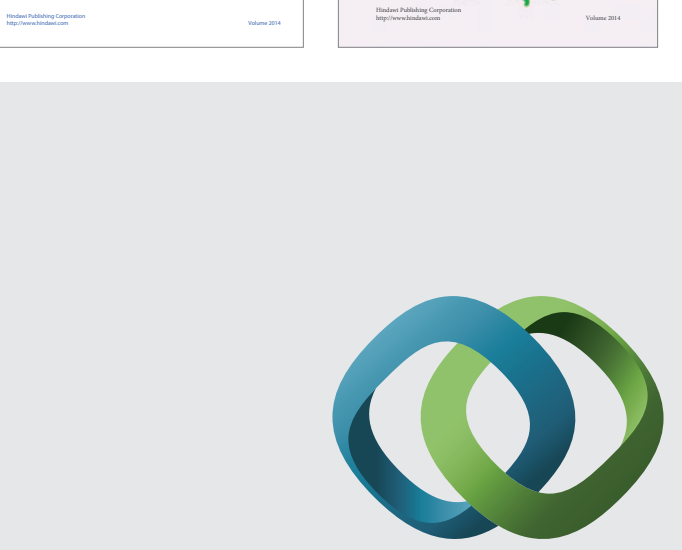

\section{Hindawi}

Submit your manuscripts at

http://www.hindawi.com
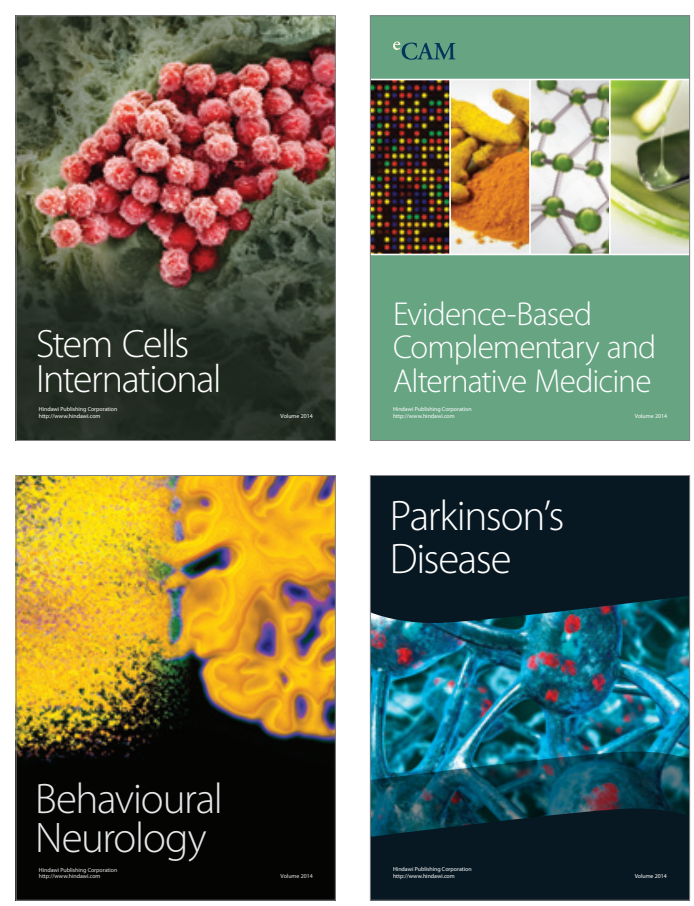

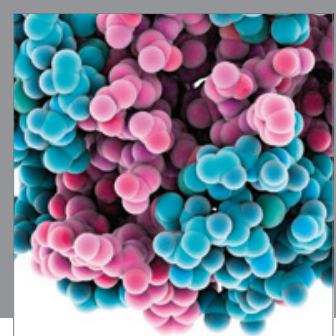

Journal of
Diabetes Research

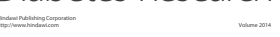

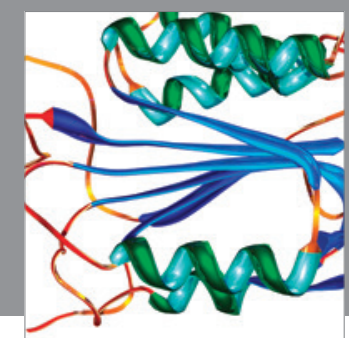

Disease Markers
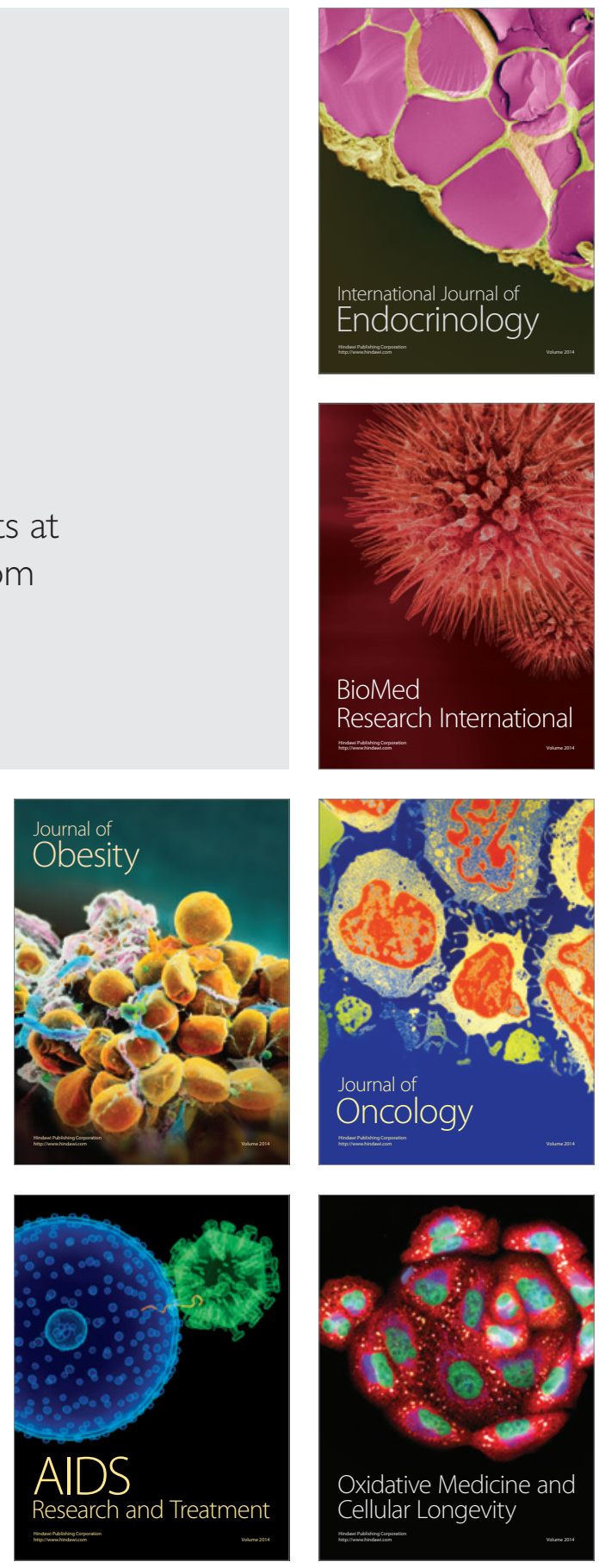